\title{
Una práctica negra que ha ganado a los blancos: símbolo, historia y devotos en el culto al Señor de los Milagros de Lima (siglos XIX-XXI)
}

\author{
Julia Costilla
}

Universidad de Buenos Aires

RESUMEN

El culto al Señor de los Milagros se manifiesta en la ciudad de Lima cada mes de octubre con una imponente convocatoria durante sus procesiones y se reactualiza en las prácticas de sus miles de fieles alrededor del mundo. Como parte de una investigación mayor orientada a indagar en la historia de este símbolo religioso desde mediados del siglo XVII, me propongo aquí avanzar desde su institucionalización (1771) y seguir su trayectoria durante el periodo republicano para profundizar en cómo se forjaron los principales significados que hoy expresa este cristo entre la población peruana: una identidad nacional mestiza y una tradición afrodescendiente. Metodológicamente seguiré el abordaje de la antropología histórica, articulando fuentes de etnografía y archivo y aplicando un enfoque histórico-antropológico. Demostraré así cómo la definición del culto en tanto "práctica negra que ha ganado a los blancos" puede sintetizar el derrotero de este símbolo religioso en dos niveles: en términos de su tricentenario proceso histórico y en términos de las representaciones sobre ese proceso.

Palabras clave: Señor de los Milagros, símbolo religioso, afrodescendientes, devotos cristianos, Perú. 


\section{A Black Practice that Has Won White People: Symbol, History and Devotes in the Cult of Lord of the Miracles in Lima (XIX-XXI Centuries)}

ABSTRACT

The cult of Lord of the Miracles takes place every October in Lima with an extraordinary attendance and it renovates on the practice of thousands of devotes around the world. Within a larger study of the history of this symbol from XVII century, I will follow him from his colonial institutionalization (1771) to his republican trajectory in order to explore how his mayor meanings were made up: a mestiza national identity and an afrodescendent tradition. Methodologically, I will use the approach of historic anthropology, with ethnographic and archive sources and with an anthropological-historical point of view. In this way, I will demonstrate how the cult definition as "black practice that has won white people" can summarize the itinerary of that symbol on two levels: in terms of his tricentenary historical process and in terms of representations about that process.

Keywords: Lord of the Miracles, religious symbol, afro-descendents, Christian devotes, Peru. 


\section{INTRODUCCIÓN}

A pocos años de celebrar su 350 aniversario, el culto al Señor de los Milagros se manifiesta anualmente con una imponente convocatoria durante sus procesiones tradicionales en la ciudad de Lima y se reactualiza en las prácticas de sus miles de fieles alrededor del mundo. Entre ellos, se destacan quienes integran la Hermandad del Señor de los Milagros de Nazarenas (en adelante, Hermandad), constituida en la capital peruana pero replicada en las distintas ciudades hacia donde la población nacional comenzó a migrar, en sucesivas oleadas, desde las primeras décadas del siglo XX.

El presente trabajo se desprende de una investigación mayor orientada a reconstruir la historia de este símbolo religioso desde mediados del siglo XVII (cfr. Costilla 2014), cuando la imagen fue pintada en el muro de una humilde ermita donde los negros de la ciudad se reunían habitualmente (cfr. Costilla, 2011, 2015) (figura 1). Pasados 120 años, el culto llegó a consolidarse con la inauguración de su santuario a fines del siglo XVIII. Mientras que su surgimiento, en 1651, estuvo alentado por el párroco y los feligreses del barrio de Pachacamilla —especialmente los negros de una incipiente cofradía reunida en su honor, secundados por los jesuitas de la ciudad—, su consolidación en 1771 fue precedida de sucesivos homenajes a la imagen por autoridades civiles y eclesiásticas: virreyes, miembros del cabildo, arzobispos y órdenes religiosas. Allí se destacaron, además, las dos instituciones que actualmente continúan a cargo del culto: la mayordomía del Cristo, como parte de una hermandad de cargadores, cantoras y sahumadoras, y la congregación religiosa que ha custodiado la imagen desde 1700: el Monasterio de Nazarenas (figura 2). Al mismo tiempo, la devoción fue conformándose en torno a una imagen reconocida como milagrosa y, en declaración del Cabildo ${ }^{1}$, consagrada como guardiana de la ciudad frente a los sismos que usualmente la

Certificaciones, 1715. 
afectaban (Costilla 2015) ${ }^{2}$. Así, desde los terremotos del año 1687, las fechas 18 , 19 y 20 de octubre permanecieron como conmemorativas de esa protección, marcando el inicio de las tradicionales procesiones con las andas del Cristo (figura 3).

Partiendo de esta profundización en la historia colonial del símbolo (Costi1la 2011, 2014, 2015), me propongo aquí avanzar desde su institucionalización (1771) y seguir su trayectoria durante el período republicano para poder revisar la actuación de quienes sostuvieron su reproducción y consolidaron su vigencia actual. Si entendemos a la imagen del Señor de los Milagros como símbolo religioso, - es decir, como entidad sagrada polisémica integrada en un sistema de representaciones y prácticas (Durkheim, 1968 [1912]; Ricoeur, 1976; Turner, 1980; Geertz, 1987; Carvalho, 2000)—, en la larga tradición del culto podemos encontrar las evidencias - fácticas y discursivas - de los distintos significados que fue recibiendo la imagen para la población peruana. Dado que los más movilizados actualmente son una identidad nacional mestiza y una tradición afrodescendiente, el objetivo será entonces analizar cómo ambos significados fueron forjados en la historia de este símbolo cristiano, evaluando en qué medida se fundamenta históricamente una definición como la que da título a este trabajo.

Aunque esto implica dejar de lado una profundización en otros significados movilizados en torno al Cristo, supone igualmente partir del símbolo en tanto «arena de lucha» (cfr. Volóshinov 2009 [1929]: 47), en especial entre significados que pueden considerarse hegemónicos y aquellos que surgen de variadas apropiaciones. La imagen del Señor de los Milagros será considerada entonces como un capital simbólico tensionado por distintos actores dentro del campo religioso peruano (Bourdieu, 2009). De esta manera, respecto del papel de los negros, no se ha buscado rastrear en las prácticas devotas los indicios de tradiciones culturales y religiosas de raíces africanas. A los efectos de este trabajo basta con comprobar que, en tanto símbolo religioso, ha sido apropiado por limeños afrodescendientes, y que es actualizado como elemento que identifica y congrega a este sector socioétnico (cfr. Arrelucea y Cosamalón 2015).

En este punto, cabe señalar que entiendo a las identidades colectivas como identificaciones, es decir, como procesos activos de autoadscripción, categorización y reconocimiento compartido (Brubaker \& Cooper, 2001). Son estos procesos los que guiarán el empleo analítico de las denominaciones negro -indistintamente a afrodescendiente- , blanco, mestizo, criollo, consideradas ante todo

Sobre el rol de afrodescendientes, jesuitas y autoridades en la consolidación colonial del culto véase también Sánchez 2002. 
como categorías socio-étnicas (Valdivia 2013; Arrelucea y Cosamalón 2015). ${ }^{3}$ Aunque en términos nativos — con las variaciones históricas correspondientes ${ }^{4}$ las clasificaciones oscilen entre criterios raciales (o fenotípicos), culturales, e incluso de clase, para los fines de esta investigación interesa destacar la dimensión étnica de estas categorizaciones.

La perspectiva metodológica empleada será la de la antropología histórica, donde se combinará un método histórico-etnográfico con un enfoque históricoantropológico (Costilla, 2016). Con relación al primero, se articulan fuentes escritas, orales y visuales obtenidas del trabajo de campo con el abordaje de documentación de archivo $^{5}$. De la indagación crítica y la compulsa de estas diversas fuentes he podido reconstruir los principales hechos de esta historia, así como también los discursos y significados desplegados en torno a la imagen. Estos últimos son los que orientarán un enfoque analítico apoyado en los marcos teórico-conceptuales de la antropología. Así, tanto para la evidencia histórica como para la etnográfica, el análisis se centrará en las lógicas particulares de las prácticas y discursos identificados, en comprender el punto de vista de los actores o «nativos» (Geertz, 1994; Lorandi, 2012).

3 Es sabido que tales términos clasificatorios han sido resignificados a lo largo del período colonial y de la historia de los estados-nacionales americanos, con marcadas influencias de los discursos científicos y activistas. Sobre estos temas puede verse: Bernand, Carmen (2001). Negros esclavos y libres en las ciudades hispanoamericanas. Madrid: Fundación Histórica Tavera; Araya Espinoza, Alejandra y Jaime Valenzuela Márquez (2010). América colonial: denominaciones, clasificaciones e identidades. Santiago de Chile: RIL editores; Kleidermacher, Gisele (2011). Africanos y afrodescendientes en la Argentina: invisibilización, discriminación y racismo, RITA 5 [en línea] (15/12/2011). Cfr. también: Alto Comisionado de las Naciones Unidas para los Derechos Humanos (2002). Declaración y Programa de Acción de Durban. Conferencia Mundial contra el Racismo, la Discriminación Racial, la Xenofobia y las Formas Conexas de Intolerancia. Bogotá: ONU.

4 Sobre este tema puede verse Bernand (2001).

5 Recuperados en distintos repositorios de Lima, y sitios web institucionales (Arzobispado de Lima, Hermandad, etc.), se han consultado desde documentos oficiales (reglamentos, actas, cartas y notificaciones) hasta folletería, entrevistas y artículos sobre la historia del culto. Entre la bibliografía confesional, se emplearon como fuentes dos completas obras sobre el culto, ambas contemporáneas: la del historiador jesuita Rubén Vargas Ugarte y la de su discípulo Raúl Banchero Castellano, quien como miembro de la Hermandad durante 43 años, y con nuevos documentos desarrolló una profunda investigación. También se revisaron fuentes periodísticas (nacionales y locales), publicaciones y documentación oficial del gobierno de Lima (capitular y municipal) y las compilaciones y compendios sobre el culto elaboradas por autores limeños (entendidas como publicaciones testimoniales proveedoras tanto de datos históricos como de apreciaciones nativas). El trabajo de campo en la ciudad de Lima se realizó en el año 2008, donde se pudo participar de los preparativos del festejo anual y sus distintas procesiones. 
Ordenaré el análisis siguiendo tres etapas: una primera (1771-1883), que partirá de la transición a la república hasta la consolidación de la Hermandad; una segunda (1883-1955), que llegará hasta la oficialización eclesiástica del culto, y una tercera (1955-2010), que culminará en el año de la declaración oficial del Cristo como Patrono del Perú. He optado por esta perspectiva de larga duración en la medida en que solo un análisis de la trayectoria completa del culto me permitirá desarrollar el objetivo planteado. Apoyándome entonces en reconstrucciones personales y en estudios previos (Stokes 1987 en Panfichi 2000 y Arrelucea y Cosamalón 2015; Vargas P. 1990; Rostworowski 1992; Escalona y Gutiérrez 1993; Sánchez 2002; Espezúa 2004; Arrelucea y Cosamalón 2015), profundizaré en los actores que reprodujeron al símbolo a través de la historia peruana para analizar hasta dónde es posible definir al culto como "una práctica negra que ha ganado a los blancos" ${ }^{6}$.

\section{ENTRE LA TRANSICIÓN A LA REPÚBLICAY LA CONSOLIDACIÓN DE LA HERMANDAD (1771-1883): ESTABILIDAD Y CONTINUIDAD DEL CULTO}

Luego de un período inicial de crecimiento y consolidación ${ }^{7}$, esta etapa del culto, signada por el ocaso colonial y las primeras décadas del gobierno peruano, puede caracterizarse como de relativa estabilidad. Esto se observa sobre todo durante la primera mitad del siglo XIX, probablemente debido al agitado contexto y al proceso secularizador que acompañó la formación de las repúblicas americanas. También porque en la construcción de una incipiente identidad peruana recibió mayor protagonismo la patrona nacional santa Rosa de Lima, más vinculada con las aspiraciones criollas (Hampe, 1996; Mujica, 2001). La devoción al Cristo de Pachacamilla, con su santuario desde 1771 y sus procesiones desde 1687, se movilizaba especialmente tras los terremotos: los dos más fuertes, en 1828 y 1860, habrían deteriorado la iglesia y el monasterio sin que el mural recibiera daños ${ }^{8}$. Estas prodigiosas resistencias reavivaban la veneración al Cristo, siendo clave también la promoción del monasterio en pos de recaudar fondos para sus obras $^{9}$ y los reconocimientos de la Santa Sede ${ }^{10}$.

Herald $1955 ?$

Es este el que las fuentes suelen presentar como «historia» del culto (1651-1771).

Síndico Juan Salazar en 1868 (en Vásquez de Novoa, 1868 [1766]).

Documento del Archivo Nacional, 23 de junio de 1828 (cit. en Banchero, 1972, p. 231).

En 1861 le concedió a su altar la gracia de ser privilegiado (Vargas U., 1966; Banchero, 1972). 


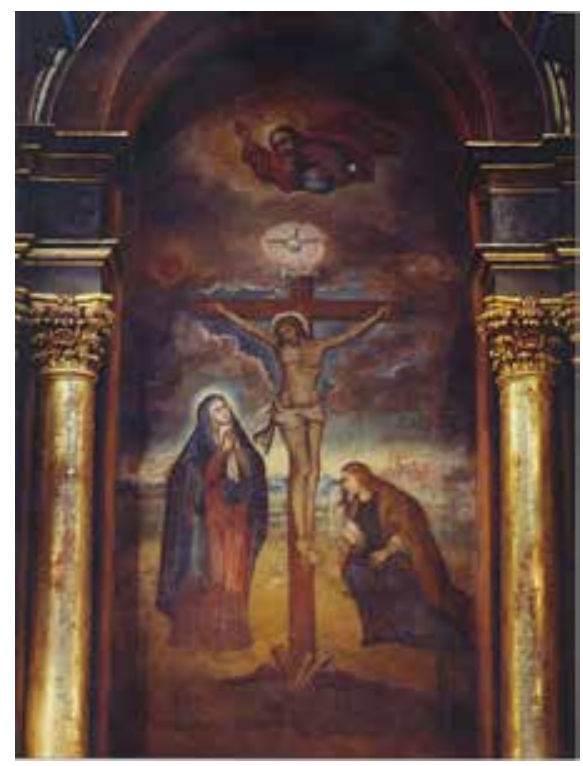

Figura 1. Imagen mural del Señor de los Milagros.

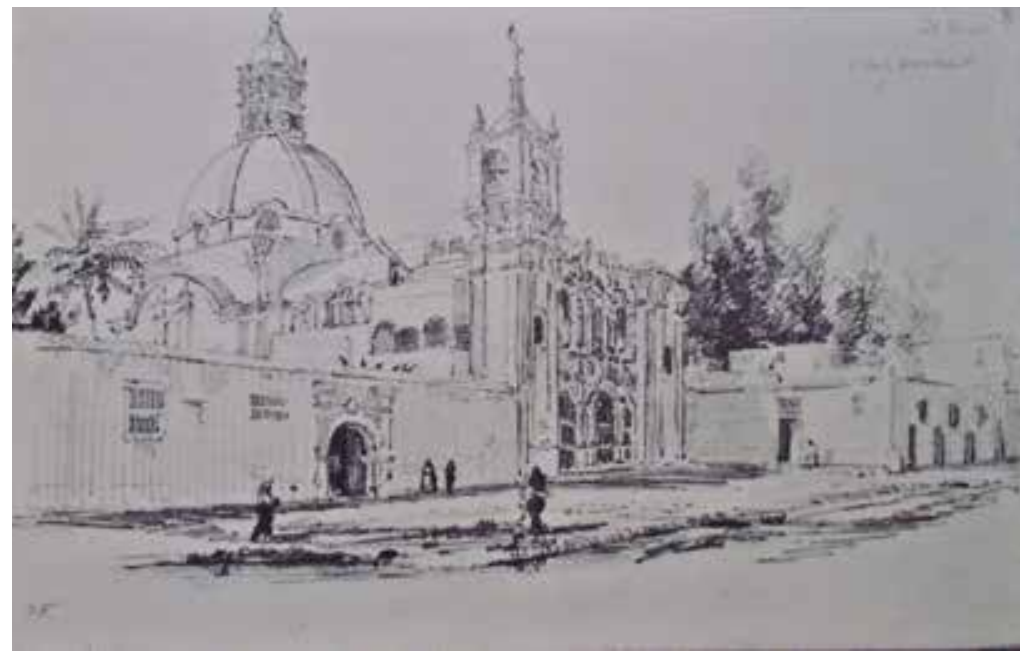

Figura 2. Santuario del Señor de los Milagros y Monasterio de las Nazarenas, dibujo de $1838^{11}$.

11 Fuente: «Lima de siempre». Skycraperscity.com. Los Ángeles; Rotterdam. 2/7/2010. (agosto 2013) 
La sucesión de mayordomos de la imagen reflejó, en parte, esta continuidad del culto. El cargo, que aparece en las fuentes equiparado al de «síndico del Monasterio» $\mathrm{y}$ «recaudador de limosnas», había surgido con una designación episcopal hacia 1671 y tuvo su mayor exponente en la figura de quien lo ocupó durante treinta años desde 1684: el español Sebastián Antuñano, quien inició las procesiones y gestionó la incorporación de las religiosas nazarenas. Desde su muerte, en 1717, se indican prolongadas interrupciones en la mayordomía hasta $1880^{12}$, lo cual sugiere que el culto no contaba aún con la solidez suficiente como para mantener una dinámica propia. Sin embargo, otros hechos muestran que su reproducción pudo sostenerse gracias al accionar de las religiosas del convento nazareno, institución que permaneció como guardiana del santuario ${ }^{13}$, y al de los propios devotos, que generación tras generación irían dando lugar a la definitiva consolidación de una hermandad religiosa.

\section{Una ansiada congregación}

La formación de una cofradía del Señor de los Milagros venía siendo promovida desde la primera mitad del siglo XIX por las religiosas y por iniciativas particulares de vecinos. Las expresiones más cercanas a esta institución eran hasta el momento cuatro «cuadrillas» de cargadores de la imagen que se habían formado para una procesión extraordinaria en $1766^{14}$ (Costilla, 2011). A ellas vinieron a sumarse tres cuadrillas más entre 1858 y 1873: dado que sus contextos de fundación ilustran cuál era la situación del culto, me detendré brevemente en cada uno de ellos.

La creación de la quinta cuadrilla en 1858 se concretó en una ceremonia con asistencia de autoridades limeñas. ${ }^{15}$ Siendo que el acto se producía al año de haberse restituido el gobierno municipal tras dieciséis años de receso, no parece casual esta solemne institución de una cuadrilla del Cristo - la primera en casi cien años - ante la presencia del primer alcalde de Lima. Cinco años después,

12 Las fuentes que recuperan la historia de este cargo (Banchero, 1972, pp. 298-300; Hermandad, 2008) señalan una sucesión interrumpida por interregnos de hasta cinco décadas (1717-1766; 1771-1828; 1828-1868; 1869-1880); sin embargo, esta no se condice con otras referencias al cargo ocupado, registradas para años como 1846 (Benito, 2005; Militantes, 2008) o 1873 (Autos 1873).

13 No por nada la mayordomía en este período estuvo representada por el «síndico del Monasterio», figura directamente ligada a las religiosas.

14 Estas derivaban a su vez de una cofradía del Monasterio que funcionaba espontáneamente desde 1760 (Banchero, 1972).

15 Hermandad 2013. 


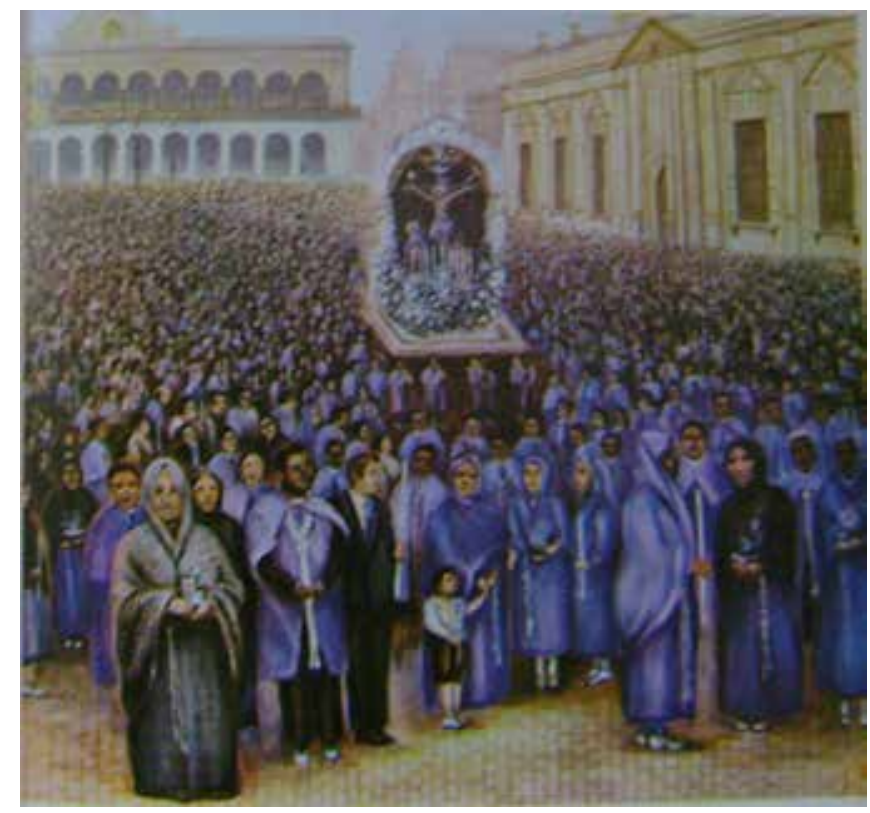

Figura 3. Procesión a mediados del siglo XIX, según A. Rodríguez Álamo (Banchero, 1976, p. 81) ${ }^{16}$

una sexta cuadrilla se creó cuando nueve hermanos cereros y mixtureros, dirigidos por la priora del convento, se reunieron para participar de las procesiones.

En los diez años transcurridos hasta constituirse la cuadrilla séptima, se percibe en la Iglesia limeña un renovado interés por esta imagen, por dar a conocer su «verdadera historia» y por rendirle veneración en recorridos procesionales. Un conflicto entre las procesiones nazarenas tradicionales y las que promovía un beaterio cercano, con su propia imagen del Señor de los Milagros, revela disputas no solo por las limosnas y las entradas de sus mayordomías sino incluso por la propiedad del culto: el monasterio nazareno se arrogaba derechos por tener la «verdadera» imagen del Cristo. Argumentaba el síndico que la veneración que anualmente se le rendía «sin duda se perderá con la duplicación de la procesión que de cuatro años a esta parte se está sacando; pues del Templo de Santa Liverata ha salido dicha procesión, usurpando los derechos que tiene el Monasterio que

16 El visible hábito morado identifica — e integra - a las religiosas y los cofrades nazarenos. 
represento» ${ }^{17}$. La creación de una cuadrilla en ese mismo año del conflicto sugiere una intención de reforzar esa procesión, que ya contaba con «competencia».

En 1878 se funda la Sociedad del Señor de los Milagros de Nazarenas de Auxilios Mutuos (Vargas U., 1966; Cruz, 1984) ${ }^{18}$, integrada por miembros de las siete cuadrillas y devotos del vecindario. Aunque no fue una hermandad de cargadores ni el origen de la tradicional Hermandad, fue una institución unida a ella y nos marca la primera asociación formal de fieles de este Cristo. Se daba además en un contexto donde, finalizada la primera etapa de gobiernos militares en 1872, adquiría mayor presencia este tipo de asociaciones civiles (Ulrich, 2010) $\mathrm{y}$ en un proceso de cambios económicos donde se fue innovando el contenido de las agrupaciones piadosas (Cruz, 1984). Por otra parte, era una fundación que precedía — casual o causalmente - al período de definitiva sucesión en la mayordomía del Cristo.

Queda claro entonces que el culto continuó desarrollándose a lo largo de toda esta etapa. A pesar de los interregnos en la mayordomía y del agitado contexto sociopolítico, hubo un sostenido reconocimiento a la imagen por los fieles que siguieron movilizándose - al menos quienes participaban como cargadores, sahumadoras, cereros y mixtureros - e incluso de ciertas autoridades - desde romanas hasta municipales-, y exceptuando los años más conflictivos ${ }^{19}$, continuaron las tradicionales procesiones de octubre. Como apuntaba el síndico de 1873, en ese contexto de avance secularizador donde «ha venido en algún detrimento el culto católico», la procesión del Señor de los Milagros «todavía conservaba [...] la veneración y el respeto que desde tiempo inmemorial tenía en los fieles de esta Capital $»^{20}$. Pero (salvando la elocuencia de ciertas imágenes; ver figura 3) sobre la adscripción étnica de los fieles poco se decía; será en las próximas etapas donde cobre relevancia este carácter del culto.

17 Autos 1873: f. 1. El año que señala la cita coincide con la publicación de un reconocido manuscrito sobre el culto (el compendio del funcionario real Vásquez de Novoa, de 1766); por lo cual el surgimiento de estas procesiones «paralelas» puede estar vinculado con esa promoción del culto.

18 En su Reglamento (1925) aparece con la denominación Hermandad de Cargadores y Zahumadoras..., lo cual genera una confusión entre esta institución mutualista y la tradicional Hermandad (véase Banchero, 1976; Espezúa, 2004).

19 En 1871, por ejemplo, la procesión fue retrasada hacia el 28 de octubre debido a la agitación por las elecciones generales (El Comercio 27/10/1871, cit. en Banchero, 1972). Luego tuvo una suspensión durante los dos años de ocupación chilena en la ciudad (1881-1883) (Municipalidad, 1997).

Autos 1873: f. 1. 


\section{MULTIPLICACIÓN Y DIVERSIFICACIÓN: ENTRE LA CONSOLIDACIÓN DE LA HERMANDAD Y LA INSTITUCIONALIZACIÓN ECLESIÁSTICA DEL CULTO (1883-1955)}

Desde fines del siglo XIX, y sobre todo en las primeras décadas del XX —época clave en la formación de los estados-nación americanos ${ }^{21}$ - el culto fue revitalizándose: se aceleró el crecimiento en el número de devotos y se multiplicaron sus imágenes en América y Europa. Dejando este último proceso para desarrollar en la etapa siguiente, me concentraré aquí en la diversificación del culto y su mayor oficialización.

\section{Nuevos devotos}

Tanto en las procesiones como en la Hermandad, durante este período el culto fue creciendo y expandiéndose entre nuevos sectores sociales (Stokes 1987 cit. en Panfichi 2000 y Arrelucea y Cosamalón 2015). Respecto del aumento cuantitativo, para la procesión de 1887 se concretó la fundación de una octava cuadrilla de cargadores, la primera que se creaba por iniciativa de un mayordomo. A esta le siguieron otras siete entre 1904 y 1954, movilizadas por el sacristán de la iglesia nazarena o por iniciativas de devotos agrupados ${ }^{22}$.

Pero ¿quiénes eran esos devotos hermanados en las cuadrillas del Cristo? Las distintas fuentes coinciden en señalar que hasta ese momento se trataba de población negra, pero a medida que la devoción fue extendiéndose entre criollos y mestizos (incluso asiáticos ${ }^{23}$ ), también fue abriéndose a ellos el espacio institucional del culto. Se afirma así que, al menos desde el año 1928, comenzó a admitirse a miembros de otros grupos étnicos en la Hermandad. ${ }^{24} \mathrm{Al}$ mismo tiempo, independientemente de su adscripción étnica, comenzaría a registrarse también la presencia de hombres y mujeres de sectores sociales más altos: si hasta los años 1920 los cofrades provenían mayormente de gremios de adoberos,

21 Para este tema puede verse: Anino, Antonio y Françoise-Xavier Guerra, coords. (2003). Inventando la Nación. Iberoamérica. Siglo XIX. México: FCE; Funes, Patricia (2006). Salvar la nación: intelectuales, cultura y politica en los años veinte latinoamericanos. Buenos Aires: Prometeo.

22 Hermandad 2013. Un rasgo que compartieron desde la década de 1930, en un escenario de gobiernos militares de corte elitista (Burga, 1999), fue la formación de asociaciones de auxilios mutuos, mostrando así que la devoción daba paso a otras finalidades sociales.

23 Provenientes de la inmigración china y japonesa que recibió el Perú desde mediados del siglo XIX.

24 Benito 2005; Militantes 2008. 
cocheros, estibadores del puerto, etc., progresivamente fueron incorporándose profesionales, ejecutivos, funcionarios, ministros de gobierno, oficiales de las fuerzas armadas y policiales y figuras del deporte, las artes y el espectáculo ${ }^{25}$.

Fuera de la Hermandad, la participación en el culto se visibilizaba especialmente en las procesiones anuales, registradas en imágenes y relatos de publicaciones de la época ${ }^{26}$. El reconocido escritor Mariátegui, por ejemplo, describía a los devotos de 1917 como «zambos, negros o mestizos» (Mariátegui, 1917). En 1921 se señalaba que:

$[\ldots]$ a pesar de la intromisión de fieles «decentes», siempre dominan en la procesión de los Milagros las gentes de oscuro color. El hermano moreno que pide limosna para el Señor o impone el orden a puñadas es un símbolo fidelísimo de lo que significa la procesión. Después se ha introducido la novena y la procesión de los blancos (Mundial, 1921 [cursivas en el original]).

Es evidente entonces que el culto había comenzado a cambiar y esto resultaba, como veremos después, de su apropiación por parte de las elites políticas. En un momento donde distintas prácticas culturales comenzaron a ser consideradas como constitutivas de la nación, afloraron las tensiones entre los nuevos simbolismos tejidos en torno a esa incipiente peruanidad mestiza y simbolismos tradicionales como el vinculado a este culto afrodescendiente, que para peruanizarse debió "adecentarse" o "desafricanizarse" (Panfichi, 2000; Del Águila 1997 en Valdivia, 2013; Arrelucea y Cosamalón, 2015). Por eso las descripciones de la procesión que ofrecían periodistas y escritores de la época expresaban tanto percepciones de las elites limeñas sobre los negros — cargadas de estereotipos raciales ${ }^{27}$ - como esa desetnización del culto. Las evocaciones de los nuevos participantes referían al "perfume del pasado", "la amable tradición" y "la pompa magnífica de los días idos", a un pasado cargado de sensaciones que luego se convertirían en símbolos de la nación: el color morado, los cánticos, el olor de sahumerio y los turrones (Valdelomar, 1915). Otro escritor peruano describía en 1935 que "La procesión resulta un desfile animado de cuanto Lima encierra [...] hay aquí los mejores/ tipos de blanco y negro, del indio rojo y bayo, / del lapón, del papúa, del chino y del malayo....". (Amézaga, 1935, p. 333).

25 Entrevistado 2: empleado público, 21 de octubre de 2008; Carrera, 1950?; Vergara y Álamo, 1965; Banchero, 1972; Benito, 2005; Hermandad, 2013.

26 Pueden verse por ejemplo las fotografías publicadas en la revista limeña Variedades, entre1908 y 1931 (ej. 1909, p. 804, Archivo del Cabildo Metropolitano).

27 Estos reforzaron a su vez a los de origen colonial y esclavista (Arrelucea y Cosamalón, 2015). 
Ya para 1950, un artículo donde se afirmaba que comenzaban a verse «elementos selectos de la sociedad confundidos con el pueblo» se refería a las «murmuraciones rabiosas de los cofrades que hasta hoy según parece, no acaban de tragarse esta intromisión de los blancos en cosas que ellos dicen fueron suyas y para ellos desde su nacimiento» (Carrera, 1950? [las cursivas son mías]). Quienes cargaban la imagen, según otro intelectual de la época, eran ya «señorones y señoritos del mundo social, oficial y hasta diplomático» y no «los negros devotos que, por lo que vese, han quedado atrás definitivamente» (Carrera, 1954, en Toro Montalvo, 2006, p. 139). Se destacaba la «asistencia de visibles elementos de todas las esferas sociales», junto a altas personalidades del gobierno, el parlamento, la banca, el comercio y la industria (El Comercio, 1950b). Vemos, además, que se cruzan constantemente las apreciaciones étnicas, raciales y de clase. Así, una distinción entre «plebe» $\mathrm{y}$ «gente decente» enmarcaba la caracterización del culto como «práctica negra» en esta frase de mediados de los años 1950:

Hasta hace poco la Procesión del Señor de los Milagros estaba considerada como una práctica plebe. Tan etíope que en sus formas rituales se había expresado el sensualismo y fuerza de la raza esclava. Fiesta que nos revelaba el simplismo y afán exhibicionista de los mulatos. Religión que perdía su sentido íntimo para ganar en liturgia fiestera y vitalidad pueblerina. Entonces existían dos procesiones. Una de los negros o mulatos, y otra de la «gente decente» (Herald, 1955?).

La diversificación de los fieles y el incremento de las migraciones internas hacia la capital (cfr. Manrique, 1995; Matos, 2010) llevaron también al aumento de la presencia de «mestizos y población andina $»^{28}$. Señalaba la prensa que la devoción se había generalizado en todo el Perú, «Sierra, Costa y Montaña», llegando al santuario fieles de los lugares más lejanos de la república, incluso «turistas extranjeros». (El Comercio, $1950 \mathrm{a}$ y b).

Ahora bien, la década de 1950 fue también un momento clave en términos eclesiásticos. La fecha propuesta como fin de esta segunda etapa (1955) coincide con la bisagra entre dos períodos de la Iglesia peruana: uno (1930-1955) caracterizado por el surgimiento de un nuevo laicado militante — que con emblemas y cantos procuraba inculcar sentidos de pertenencia entre los católicos-y otro (1955-1968) jalonado por dos importantes concilios episcopales ${ }^{29}$ que impulsaron una renovación de la Iglesia. En consonancia con esos dos contextos, entonces, la

28 Entrevistado 2: empleado público, 21 de octubre de 2008.

29 La primera Conferencia Episcopal de América Latina (1955) y el Concilio Vaticano II (1959) (Klaiber, 1996). 
historia del culto tuvo en 1955 dos hitos destacados: se eligió el himno al Señor de los Milagros actualmente cantado en las procesiones (creado por una compositora de la élite limeña) y la Hermandad recibió el reconocimiento oficial del Arzobispado (Banchero, 1972, 1976; Benito, 2005; Arzobispado, 2006; Hermandad, 2008; Militantes, 2008), hecho que nos marca el inicio de la siguiente etapa del culto. Pero previamente a esta institucionalización episcopal de la Hermandad, el símbolo religioso ya venía cosechando su aceptación política y eclesiástica.

\section{Reconocimientos oficiales}

El crecimiento del culto en la primera mitad del siglo XX se vio impulsado sobre todo por una serie de actos y eventos tendientes a su oficialización (cfr. Stokes 1987, en Panfichi, 2000; Vargas P., 1990; Escalona y Gutiérrez, 1993; Arrelucea y Cosamalón, 2015). Desde el oncenio de Augusto Leguía (1919-1930), de tendencia popular, las procesiones comenzaron a contar con presencia e intervención de autoridades civiles y eclesiásticas, encabezadas por el presidente y el arzobispo ${ }^{30}$.

En ese contexto, se destacaron dos ceremonias asociadas a los festejos de centenarios seculares: una de ellas en conmemoración de la independencia nacional, cuando se bendijeron nuevas andas de plata para la imagen procesional en octubre de 1922, y la otra en 1937, a dos años de celebrarse el cuatricentenario de la fundación de la ciudad de Lima, cuando las renovadas andas recibieron un escudo limeño como ofrenda del municipio metropolitano (Mundial, 1921; Alcaldía de Lima, 1937; Banchero, 1972; Municipalidad de Lima, 1997). Mientras el primer acto, acompañado por el padrinazgo del presidente Leguía, puede ser entendido en el marco de los esfuerzos del gobierno por lograr un acercamiento entre el Estado y la Iglesia (Escalona y Gutiérrez, 1993), el segundo ha sido planteado como confirmación republicana del reconocimiento del Cabildo hacia la imagen, aquel que se había plasmado en el juramento de $1715^{31}$. Ambos rituales expresaban entonces la concesión de un carácter más oficial a la procesión Otras conmemoraciones se vincularon propiamente con la historia de la imagen: el tricentenario de su creación (1651) y el de su primer milagro, conservarse tras un terremoto (1655). Justamente en esos momentos propicios fue cuando se concretaron las necesarias refacciones en el santuario y en las dos imágenes de culto (el mural

\footnotetext{
30 Junto a los devotos se dejaban ver ministros de Estado, diplomáticos, legisladores, jefes de las fuerzas armadas, concejales, alcaldes, sacerdotes y representantes de órdenes religiosas (Carrera, 1950?).

31 Banchero, 1976 (en este caso también devoto).
} 
y las andas procesionales). Gracias al apoyo económico estatal y eclesiástico, la inauguración del renovado templo pudo celebrarse en 1955 con destacadas y solemnes ceremonias. (Dirección General de Culto, 1955; El Comercio, 1952, 1955; Banchero, 1972).

Fue en esta segunda etapa, entonces, cuando comenzó a fraguarse en torno al Cristo un imaginario nacionalista. La población limeña, golpeada por los efectos de la guerra y las posteriores crisis que atravesó la sociedad nacional (Manrique, 1995; Burga, 1999), encontraba en el culto no solo un ámbito para fortalecer su fe sino especialmente un valioso referente identitario. Con esa base, el símbolo fue movilizado especialmente desde un Estado donde las élites políticas, económicas e intelectuales exaltaron su carácter mestizo, como representación de una ciudad y de una nación fundadas sobre diversas tradiciones culturales (cfr. Rostworowski, 1992; Benito, 2005). Como se comprobará en la siguiente etapa, el símbolo religioso oficializado fue afianzando su lugar dentro del campo religioso nacional, siendo exhibido y reconocido cada vez más como un signo de la nación peruana y, al mismo tiempo, de una tradición afrodescendiente. A su vez, comenzaba a ser activado como un capital simbólico clave dentro del campo político, nacional y metropolitano ${ }^{32}$.

\section{EXPANSIÓN Y PATRONAZGO (1955-2010): LA VIGENCIA DEL «CRISTO MORENO»}

Esta última etapa estuvo signada por la extensión del culto hacia otras ciudades del mundo, mientras la devoción local siguió fortaleciéndose y continuaron los reconocimientos oficiales a la imagen. Asimismo, como expresa la denominación incluida en el título, logró revertirse definitivamente el desdibujamiento del accionar de los afrodescendientes y de su presencia clave en la historia del culto ${ }^{33}$.

\section{Hermandad y fieles}

Respecto de la Hermandad, legitimada ya como institución dependiente del Arzobispado, continuaron creándose nuevas cuadrillas hasta la década de 1960

32 Incluso puede ser entendido como un índice de las relaciones entre Estado e Iglesia (agradezco a los evaluadores anónimos del manuscrito por sus aportes en este punto).

33 Esta invisibilización de los afroperuanos, observada en las fuentes históricas, se ha dado también en términos sociales, políticos, económicos, jurídicos y culturales. Sobre este tema puede verse: Arroyo (2006); Rodríguez Pastor (2008); Rojas (2008). 
por iniciativas de devotos que ya actuaban en las labores del santuario y sus cultos. Asimismo, en sintonía con las conquistas femeninas de la época, se integraron oficialmente (entre 1962 y 1967) las hermanas cantoras y sahumadoras que participaban de las procesiones desde tiempos coloniales. Es decir que fue un período de activa presencia del laicado católico combinada con una pastoral eclesiástica que - Concilio II mediante - manifestaba su mayor acercamiento a los fieles y sus devociones. En este proceso, concretamente para una Misión Conciliar que en 1967 se realizó en la arquidiócesis de Lima (Klaiber, 1996), la imagen del Señor de los Milagros resultó condecorada por el arzobispo como «Primer Misionero del Perú» (Banchero, 1972; Hermandad, 2013) ${ }^{34}$.

Otro efecto más o menos indirecto de la influencia conciliar ${ }^{35}$ debió haber sido el mayor reconocimiento a la presencia de los negros en el culto. Así, tanto medios locales como del Vaticano se referían al «esclavo negro» que pintó al Cristo (Vaticano, 1964, cit. en El Comercio, 1968). Incluso el arzobispo lo señalaba como «precursor» de la Hermandad: «fue un hombre, sometido a la injusta condición de esclavo, arrancado de las tierras africanas, quien exteriorizando sus vivencias cristianas, plasmó sobre un rústico muro lo que constituía su riqueza personal [...] y resultó precursor de la hermandad al pintar esa imagen» (Banchero, 1972, $\mathrm{p}$. 287 [cursivas en el original]). Las propias crónicas confesionales sobre el culto hicieron eco de esta tendencia con referencias más explícitas al «esclavo angola» y resaltados pasajes donde se defendía a este sector social de las acusaciones de las que eran objeto (véase Banchero, 1976, pp. 10-20). Pero fue especialmente en el ámbito de la Hermandad donde, junto a otros tres elementos - el escudo de Lima, un roble (símbolo de Vizcaya, provincia española del primer mayordomo) y el Monasterio-, se plasmó la agencia de los negros en tanto signo de la cofradía y del culto (figura 4) (Costilla, 2011).

34 Cabe agregar que la extendida participación en el culto y su creciente masividad (convocaba a casi medio millón de devotos) no estuvieron exentas de reacciones conservadoras y críticas a ciertas manifestaciones que, según se afirmaba, desvirtuaban la «finalidad penitencial» de las «tradicionales procesiones octubrinas» (Baldarrago, 1968; El Comercio, 1970; Banchero, 1972, pp. 352-353).

35 Conjugada con la apertura global hacia una valorización de la diversidad cultural. 


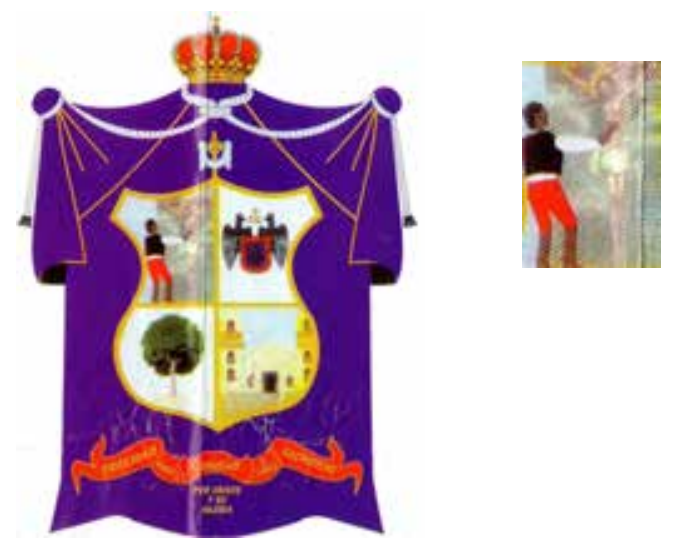

Fig. 4. (a) Escudo nazareno y (b) detalle del cuadrante superior izquierdo (Hermandad, 2013)

Acciones estatales y eclesiásticas: entre intervenciones y legitimaciones

$\mathrm{Si}$ atendemos a las ceremonias anuales y extraordinarias a lo largo de las cinco décadas que comprende esta última etapa del culto, observamos que el símbolo fue igualmente celebrado y legitimado como apropiado desde particulares intenciones políticas (tanto seculares como eclesiásticas). Un ejemplo de esto se aprecia en el cruce de conmemoraciones centenarias hacia 1971, pasados tres años del golpe militar de izquierda encabezado por Velasco Alvarado: coincidieron allí los 150 años de la independencia nacional, el bicentenario de la inauguración del santuario y el tricentenario de la primera misa celebrada ante la imagen. Respecto de las ceremonias religiosas, los actos contaron con participación eclesiástica (arzobispo, Monasterio, Hermandad y devotos), pero estuvieron ausentes las autoridades nacionales y locales. Este no solo resultaba de ser un año donde la atención simbólica se concentró en el centenario patrio, sino que además reflejaba el contexto político general de tensiones entre Iglesia y gobierno. En este sentido, resulta revelador el contraste con la veneración que el Partido Aprista Peruano, enfrentado al gobierno de Velasco, brindó a la imagen por esos años (Correo Aprista, 1972; Orrego, 2008) ${ }^{36}$. Fue, por tanto, desde la asunción de un

36 La jerarquía episcopal, por su parte —que desde 1966 venía promoviendo mejoras en el convento nazareno y su comunidad religiosa - se ocupó en 1971, aprovechando su presencia en Roma y una reunión ministerial en Lima, de realzar la solemnidad de las celebraciones de octubre programando una procesión extraordinaria con indulgencia plenaria del papa ( $E l$ Comercio, 1966; Banchero, 1972). 
mandatario aprista en los años 1980 (Alan García Pérez) cuando la celebración volvió a recibir mayor solemnidad y relevancia de las autoridades seculares.

Tiempo después, pasadas las tensiones entre autoridad política y jerarquía católica que caracterizaron al primer gobierno de Fujimori [1990-1995] (Armas 1999), la llegada de un nuevo prelado a la arquidiócesis limeña en 1999 —un cardenal de tendencia conservadora (Juan L. Cipriani) - implicó un nuevo impulso de veneración al Cristo. Mientras que en las procesiones anuales la imagen comenzaba a ser homenajeada oficialmente por arzobispo, municipalidad y autoridades del Palacio de Gobierno, fue recibiendo también, en tanto símbolo religioso central, sucesivas consagraciones - papales, episcopales y estatales - como «patrono del pueblo limeño», «Patrimonio Cultural de la Nación», y finalmente, por declaración del presidente y el Congreso peruanos en el año 2010, como Patrono del Perú (Juan Pablo II, 21/09/2001; AICA, 2011).

Esta decisión venía a ser el corolario de todo ese proceso de difusión y extensión iniciado en la etapa anterior. Pero su lugar como patrono no surgía solo de la expansión del culto por el territorio nacional (cuadro 1): lo hacía también, y especialmente, por la reproducción de aquel en las distintas ciudades hacia donde la población peruana había migrado.

\section{Cuadro 1. Hermandades del Señor de los Milagros en Perú ${ }^{37}$}

\begin{tabular}{|c|c|c|c|}
\hline \multicolumn{2}{|c|}{ Departamento de Lima } & \multicolumn{2}{|c|}{ Otros departamentos peruanos } \\
\hline Provincia & Distritos con Hermandad/ & Junín & San Martín \\
\hline & Total distritos por provincia & Arequipa & Piura \\
\hline Lima & $29 / 43$ & Ancash & Tacna \\
\hline Barranca & $2 / 5$ & Cajamarca & Loreto \\
\hline Cañete & $2 / 16$ & Huánuco & Ayacucho \\
\hline Huaral & $2 / 12$ & Callao & Puno \\
\hline Huaura & $1 / 12$ & Cusco & Tingo María \\
\hline Huarochirí & $1 / 32$ & Lambayeque & Moquegua \\
\hline
\end{tabular}

37 Exceptuando el caso de la Hermandad limeña original, cuyo inicio se consigna en 1651, las demás comenzaron a crearse desde el año 1936. Fuera del departamento de Lima se conformaron hermandades numerosas alrededor de los años 1950 en ciudades como Arequipa (1950) y Cusco (1953), entre otras fundaciones contemporáneas y posteriores (por ejemplo, Piura en 1948, Cajamarca en 1956, Tacna en 1960, Lambayeque en 1979). Por razones de espacio no 


\section{El Cristo nazareno: "carta de presentación del pueblo peruano en el mundo» ${ }^{38}$}

La multiplicación de imágenes, procesiones y hermandades nazarenas en América y Europa -incluso en Asia, África y Oceanía - fue un proceso paralelo al aumento de flujos migratorios de peruanos ${ }^{39}$. Puede ilustrarse esta expansión del culto organizado tomando la constitución de Hermandades como indicador (cuadro 2).

Uno de los casos más antiguos es la procesión en la ciudad estadounidense de Hartford (Connecticut), cuyo ejemplo permite observar de qué manera se estableció el culto en un contexto migratorio. Con cientos de devotos, la celebración se realiza desde el año 1967 a partir de una copia del Cristo trasladada por un grupo de residentes peruanos. Con el acompañamiento de la sociedad local y sus autoridades estatales (gobernador, alcalde y jefe de policía) los devotos lograron conformar su Hermandad, construir una capilla e instituir en el calendario religioso la tradicional procesión con la imagen, desplegada con todos sus característicos elementos rituales y festivos: flores, cirios y sahumerios de incienso, hábitos morados, la «Marcha del Cristo Moreno», turrones de Doña Pepa y anticuchos ( $E l$ Comercio, 1968; Cisneros, 1968?; Coronado y Cisneros, 1971; Espinoza, 2008).

Hacia el final de esta etapa, una buena síntesis de sus características se observa en discursos e imágenes exhibidos desde la Hermandad. Por una parte, la institucionalidad del símbolo se refleja en los retratos expuestos en las paredes de la oficina del Mayordomo: el Virrey Amat (primer consagrador del Cristo en 1771), el Papa Juan Pablo II y el actual Arzobispo. Por otro lado, lo que el Mayordomo destaca en sus relatos sobre la historia del culto es su proyección internacional; sobre la procesión en Madrid señalaba: "lo bonito/ como he tenido la oportunidad de compartir/ había gente española/ había portugueses/ había franceses/ también participando y queriendo saber el porqué de eso/ por qué lo sacaban en andas". ${ }^{40}$

se ha podido avanzar en el desarrollo del culto en estas otras ciudades peruanas (sus sitios web oficiales pueden consultarse en portales de facebook y blogspot: Hermandad del Señor de los Milagros del Cusco. Información [facebook oficial]; Hermandad del Señor de los Milagros del Templo de San Agustín de Arequipa. Historia [blog oficial]).

38 Cardenal Cipriani en Benito (2005); Militantes (2008).

39 Especialmente a Estados Unidos, España, Italia, Francia e Inglaterra, desde la primera mitad del siglo XX, y luego hacia Argentina, Venezuela, Canadá y Japón, entre otros (cfr. Abusada y Pastor, 2008). Devociones compartidas: el culto a Santa Rosa y al Señor de los Milagros en Lima y Santiago de Chile, siglos XIX y XX. En González Miranda, Sergio y Daniel Parodi. Las historias que nos unen... estudios positivos en las relaciones peruano-chilenas, siglos $X I X-X X$. Santiago de Chile: RIL. 441-468. Salvo algunas más antiguas, la mayoría de las Hermandades data de entre 1970 y 2010.

40 Entrevistado 1: Mayordomo de la Hermandad, Lima, 30/10/2008. Aunque él se reconoce como afrodescendiente, no abordó el tema étnico ante la pregunta por la historia de la Hermandad. 
Cuadro 2. Hermandades nazarenas en el mundo (elaboración propia a partir de Banchero, 1972, 1976; Hermandad BH, s/f; Echevarría, 2010-2013)

\begin{tabular}{|c|c|c|}
\hline & País & Localidad \\
\hline \multirow[t]{9}{*}{ Sudamérica (16) } & Venezuela & $\begin{array}{l}\text { Aragua, Valencia, Caracas, Ciudad Guayana, } \\
\text { Mérida }\end{array}$ \\
\hline & Bolivia & $\begin{array}{l}\text { La Paz (una de las más antiguas, fundada en } \\
\text { 1940, con devotos de Oruro y Cochabamba) }\end{array}$ \\
\hline & Panamá & \\
\hline & Paraguay & Asunción \\
\hline & Brasil & Belo Horizonte, Río de Janeiro \\
\hline & Ecuador & \\
\hline & Colombia & Bogotá \\
\hline & Argentina & Buenos Aires, Rosario, Córdoba \\
\hline & Chile & Santiago de Chile \\
\hline \multirow[t]{3}{*}{$\begin{array}{l}\text { Norteamérica } \\
\text { (más de 60) }\end{array}$} & EEUU & $\begin{array}{l}\text { cerca de } 60, \text { se destacan las de Nueva York y } \\
\text { Hartford (la más antigua) }\end{array}$ \\
\hline & Canadá & Montreal, Ontario, Toronto \\
\hline & México & México DF \\
\hline Centroamérica (1) & Aruba & \\
\hline \multirow[t]{8}{*}{ Europa (24) } & Italia & $\begin{array}{l}\text { Milán, Génova, Bergamo, Bolonia, Florencia, } \\
\text { Nápoles, Perugia, Roma, Rimini, Trento, Torino }\end{array}$ \\
\hline & España & Barcelona, Madrid, Galicia, Valencia \\
\hline & Alemania & Colonia, Hamburgo, Munich \\
\hline & Suiza & Ginebra, Zurich \\
\hline & Francia & París \\
\hline & Bélgica & Amberes \\
\hline & Rumania & Bucarest \\
\hline & Suecia & Estocolmo \\
\hline Asia (5) & Japón & Kobe, Yamato, Isezaqui, Kakegawa, Oyama \\
\hline Oceanía (2) & Australia & Melbourne, Ingleburn \\
\hline África (1) & Egipto & Cairo \\
\hline
\end{tabular}

Cfr. Lizarzaburu, Javier (2011). Limeños de todas las cepas: "La procesión y la fe no se acabarán nunca". El Comercio [en línea] 16/10/2011. 
Puede afirmarse en consecuencia que el símbolo central de este culto, la imagen del Señor de los Milagros replicada en infinidad de representaciones materiales, ha llegado a convertirse en un verdadero signo para propios y extraños. Esto implica que, además de su carácter opaco y polisémico (cfr. Ricoeur, 1976; Turner, 1980; Geertz, 1987), alcanzó un reconocimiento público, incluso dentro del campo religioso internacional, que le confirió un carácter más claro y unívoco: la imagen como signo del Estado peruano en tanto nación mestiza y al mismo tiempo de una tradición afrodescendiente.

Dada esta historia, se ha sostenido que la mutación principal del culto ha sido que «el señor de los esclavos ha pasado a ser el de todas las razas y clases», y que a una devoción «fuertemente marcada por la experiencia del pobre» se le sumó la «presencia privilegiada de representantes y miembros de los grupos opresores» (Irarrázaval, 2006, pp. 186-187). Estas implicancias sociales -y raciales - que acompañaron la apertura étnica del culto derivan ante todo de constatar que un símbolo que representaba a los negros en tanto oprimidos pasó a ser emblema de una nación pluricultural, uniendo en una misma creencia a sus distintos sectores sociales (Rostworowski, 1992) ${ }^{41}$. Ejemplo de esto es el ¡Viva el Perú! que se exclama a continuación del Himno Nacional para iniciar las procesiones, ya sea en Lima, en Nueva York o en cualquier otra ciudad (sin olvidar, desde ya, las diferentes implicancias de hacerlo en un contexto migratorio). Pero las cuestiones de clase, más allá de la adscripción étnica, también se expresan en este culto religioso disputando sus sentidos: por ejemplo, cuando una mujer dejó escuchar su exclamación «isobreviva!» a continuación del ¡Viva el Perú! en la procesión del año $2008^{42}$.

\section{CONCLUSIONES}

He analizado aquí el proceso a través del cual el símbolo limeño del Señor de los Milagros fue reproducido y reactualizado a lo largo de la historia peruana. Al revisar su trayectoria colonial inicial, puede afirmarse que este símbolo fraguó definitivamente en 1771, representando una devoción que integraba a toda la sociedad colonial (con sus distintas etnias y estamentos) y con un significado primordial en tanto protector de la ciudad. Pero avanzando en su historia posterior, hemos visto que la imagen ha atravesado al menos tres grandes momentos,

\footnotetext{
$41 \quad$ Benito 2005.

42 Costilla (2008). Notas de campo del 18 de octubre de 2008. Lima, MS.
} 
donde las acciones de sus devotos - entre ellos dos congregaciones religiosas centrales-, junto a las de autoridades estatales y eclesiásticas, fueron forjando sus significados actuales, especialmente desde que comenzó a develarse el papel de los afrodescendientes.

La primera etapa definida, en un largo siglo entre colonia y república, mostró sobre todo un protagonismo de los fieles: cargadores, sahumadoras, cereros y mixtureros actualizaron las procesiones anuales hasta consolidar una hermandad que los congregó institucionalmente junto a las religiosas que continuaron custodiando el santuario. Allí la imagen se consagró ante todo como símbolo de un catolicismo vigente y de una Iglesia local fortalecida. Ya en el segundo período pudo verse que, con una diversificación y oficialización del culto, el símbolo pasó a ser activado sobre todo como representante de una identidad nacional mestiza. Y en ese significado étnico fueron cobrando relevancia las raíces negras de la devoción ${ }^{43}$.

¿Se trata entonces de una práctica negra que ha ganado a los blancos? Pues eso demuestra la historia. Sin embargo, es necesario precisar la afirmación. En primer lugar, la frase remite al carácter mestizo del culto, a la capacidad del símbolo para congregar fieles de distintas etnias. Pero esto, como se ha demostrado, no incluyó - al menos no solamente- a «blancos» y «negros», sino a personas de diversas adscripciones étnicas, reconocidos como criollos, mestizos, mulatos, indígenas, asiáticos, etc. Por otra parte, la citada tesis sobre la mutación principal del culto en la transformación de un símbolo de los oprimidos (los negros) en el de «todas las razas y clases», sumó cuestiones de clase - y percepciones raciales- que exigen discernir en qué medida es posible equiparar ambos cambios. Si bien la complejidad histórica de las relaciones entre etnia y clase hace que la respuesta exceda los objetivos de este trabajo, puede alegarse en principio que se trata de procesos conectados y paralelos: la incorporación de «poderosos» en el culto no se agotó en la ampliación étnica de la devoción, y viceversa.

43 Actualmente el símbolo condensa distintos niveles de identificación colectiva, entre ellos aquel que se vincula con las membresías en las hermandades y cuadrillas nazarenas: mientras que en la Hermandad los fieles se identifican con el Cristo patrono y se congregan como encargados del culto, al interior de cada «cuadrilla» la identificación y el hermanamiento se replican en los términos que cada una define (con un nombre particular, un escudo propio, etc.) (véase Hermandad, 2013). También se destacan las identificaciones de la comunidad religiosa nazarena y las de las instituciones y entidades limeñas que se involucran en las procesiones (como los miembros de la antigua Policía de Investigaciones de Perú que formó una cuadrilla en 1960, o los bomberos y demás organismos oficiales que anualmente rinden su homenaje al Cristo). 
Pero hay algo más: la situación colonial del culto ya exponía una clara participación de élites hispano-criollas (Costilla, 2011). Si confrontamos históricamente la mutación señalada, encontramos entonces que en el surgimiento del culto había «blancos» y «poderosos» y que hubo una relativa continuidad en esa presencia, al menos con las religiosas del santuario. Si bien para el período inicial (1651-1771) también podría hablarse de un símbolo de «negros» que ganó a los «blancos», el punto está en la primera etapa aquí analizada, entre el ocaso colonial y la consolidación de la Hermandad, donde el protagonismo afrodescendiente quedó evidenciado en fuentes de la época y percepciones posteriores. Como estas no destacan la participación de autoridades y elites limeñas, ni de otros sectores socioétnicos, parecería que — salvando el rol clave de las religiosas - fueron los negros de Lima los que sostuvieron al culto en ese siglo. Por ende, los cambios en el carácter socio-étnico del culto ilustran ante todo el período republicano, puntualmente la transición entre la primera y la segunda etapa aquí definidas. Fue allí cuando se manifestó una apertura del culto y desde ese momento, no antes, cuando se comenzó a subrayar el carácter "típico" de las procesiones previas y sus participantes; en definitiva, cuando comenzó a abrirse un espacio para visibilizar la impronta afroamericana de la devoción. Es decir que, paradójicamente, los negros empezaron a visibilizarse en las fuentes sobre el culto cuando la historia empezaba a desplazarlos, o al menos a subsumir sus tradiciones bajo nuevos significados de corte nacionalista.

En definitiva, la citada definición parece sintetizar el derrotero de este símbolo sagrado en dos niveles: en términos de su tricentenario proceso histórico y en términos de las representaciones sobre ese proceso. Respecto al primero, el hoy llamado "Cristo Moreno" ha sido desde su origen un símbolo que identificó a los afrodescendientes, a los miembros de la cofradía colonial y a las sucesivas generaciones de devotos y devotas que contribuyeron a su reproducción, tanto dentro como fuera de Lima. Al mismo tiempo, fue objeto de dos grandes apropiaciones por parte las elites criollas: oficializado como símbolo de la sociedad limeña colonial y de la nación peruana desde comienzos del siglo XX. En las representaciones, en cambio, la identificación del símbolo con los negros comenzó recién cuando se lo activó como símbolo peruano y sólo en calidad de tradición pasada. Instalado ya como capital simbólico clave dentro del campo religioso y político nacional, podemos preguntarnos con qué otros significados ha sido disputada esta imagen en tanto arena de lucha y qué otras definiciones sobre su historia pueden plantear los devotos y devotas peruanos. 


\section{FUENTES INÉDITAS Y PUBLICADAS}

Alcaldía de Lima (1937). [Aprobación de obsequiar escudo de la ciudad a las andas del Señor de los Milagros]. Archivo del Cabildo Metropolitano de Lima - ACML, Decretos de la Alcaldía, segundo semestre 1937, f. 408.

Amézaga, Carlos G. (1935). El Señor de los Milagros. En Lima en el IV Centenario de su Fundación. Lima: Minerva.

Autos seguidos por don Juan Salazar síndico del Monasterio de Nazarenas... (1873). Archivo Arzobispal de Lima - AAL, Monasterio de Nazarenas IV: 54.

Arzobispado de Lima (2006). Historia del Señor de los Milagros. Primera procesión. Arzobispado de Lima [sitio oficial] (agosto 2008).

Baldarrago, Marietta (1968). "Qué es lo que mueve al mar morado». Estampa 13/10/1968:9. Lima. Universidad del Pacífico (UP), Documentoteca «Benvenutto Murrieta» - DBM: XR95.56.

Banchero Castellano, Raúl (1972). Lima y el mural de Pachacamilla. Lima: Jurídica.

Banchero Castellano, Raúl (1976). La verdadera historia del Señor de los Milagros. Lima: Inti-Sol.

Carrera Vergara, Eudocio (1950?). La tradicional procesión del Señor de los Milagros. La Crónica 18/10/1950?:12. Lima. UP, DBM:XR95.16.

Carrera Vergara, Eudocio (1954). La procesión del Señor de los Milagros. En César Toro Montalvo (2006), Octubre del Señor de los Milagros (pp. 133-140). Lima: AFA.

Certificaciones y testimonios del Escribano Real Don Diego de Salazar (1715). ACML, Libro de Cabildos, $n^{\circ} 34$, f. $158 \mathrm{v}$.

Cisneros, Niko (1968?). El Nazareno en EE.UU. La Crónica (1968?). Lima. UP, DBM.

Coronado W., Vicki y Niko Cisneros (1971). El Señor de los Milagros en los EEUU. La Crónica 31/10/1971:4 (Sección: Dominical). Lima. UP, DBM: XR95.76.

Correo Aprista [Diario] (1972). Homenaje al Señor de los Milagros. Año V, 95:5. Lima. UP, DBM: XR95.84.

Dirección General de Culto (1955). La restauración de la imagen del Señor de los Milagros. El Comercio 15/2/1955. Lima. UP, DBM: XR95.26.

Echevarría, Genaro (2010-2013). Directorio de Hermandades Nazarena [blog institucional] (noviembre 2013).

El Comercio [Diario] (1950a). Ampliación del templo del Señor de los Milagros de Nazarenas. 11/1/50. UP, DBM: XR95.14. 
El Comercio [Diario] (1950b). La procesión del Señor de los Milagros. 19/10/1950:5. UP, DBM: XR95.17.

El Comercio [Diario] (1952). El templo del «Señor de los Milagros» o de las Nazarenas será ampliamente refaccionado. 22/8/1952. Lima. UP, DBM: XR95.19.

El Comercio [Diario] (1955). La refacción de las Nazarenas respeta el carácter típico de este monumento colonial. 3/8/1955:3. Lima. UP, DBM:XR95.33.

El Comercio [Diario] (1966). Cuatro monjas españolas vinieron a incorporarse al convento de las Nazarenas. 15/9/1966:5. Lima. UP, DBM: XR95.47.

El Comercio [Diario] (1968). Esclavo de nombre Pedro Cruz pintó la Imagen del Señor de Pachacamilla. 16/10/1968. Lima. UP,DBM:XR95.60.

El Comercio [Diario] (1970). Por qué va la gente a la procesión. 1/11/1970:13-15. UP,DBM:XR95.70 y 71.

Espinoza, Ruth (2008). Misa y Procesión del Señor de los Milagros en Hartford. Identidad latina (Hispanic Newspaper Connecticut) 11/5/2008 [en línea] (mayo 2013).

Herald, Tristan (1955?). Octubre, mes morado del Señor de los Milagros. Cahuide s/d. UP, DBM: XR95.23

Hermandad (del Señor de los Milagros de Nazarenas) (2008). Conferencia de Prensa. 357 años de fe y tradición. Lima: Secretaria de Relaciones Públicas de la Hermandad.

Hermandad (2013). Hermandad del Señor de los Milagros de Nazarenas [sitio oficial] (agosto 2013).

Hermandad BL (Belo Horizonte) s/f. Señor de los Milagros (2001-2011) [sitio oficial] (octubre 2013)

Irarrázabal, Diego (2006). Cristo Morado Señor de los maltratados. En César Toro Montalvo. Octubre del Señor de los Milagros. Lima: AFA S.A., pp. 183-195.

Mariátegui, José Carlos (1935 [1917]). La procesión tradicional. En Lima en el IV Centenario de su Fundación. Lima: Minerva.

Militantes de Santa María (2008). Señor de los Milagros, a ti venimos. Lima.

Mundial [Revista] (1921). Nuestro Amo y Señor de los Milagros. 75, 21/10/1921: s/p.

Municipalidad de Lima (1997). Nuestro Señor de los Milagros. Lima.

Reglamento de la Hermandad de Cargadores y Zahumadoras del Señor de los Milagros Nazarenas de Auxilios Mutuos (1925). Lima: La Moderna.

Valdelomar, Abraham (1915). Reportaje al Señor de los Milagros. La Prensa 20/10/1915: 3. 
Vargas Ugarte, Rubén (1966). Historia del Santo Cristo de los Milagros. Lima: Sanmartí.

Vásquez de Novoa, Pedro (1868 [1766]). Compendio Histórico de la Prodigiosa Imagen del Santo Cristo de los Milagros. Lima: José María Concha.

Vergara, Óscar y César Alamo (1965). 80 años cargando al Señor de los Milagros. La Crónica 24/10/1965. Lima. UP, DBM:XR95.52?

\section{REFERENCIAS BIBLIOGRÁFICAS}

Abusada Salah, Roberto y Cinthya Pastor Vargas (2008) Migración en el Perú. Lima: Instituto Peruano de Economía.

Arroyo Aguilar, Sabino (2006). Formas de vida e integración de los afroperuanos de hoy. Investigaciones Sociales, X(16), 17-50. Lima: UNMSM.

Armas Asín, Fernando (1999). Iglesia, sociedad y política de 1950 a nuestros días: un esquema de interpretación histórica. En F. Armas Asín (comp.), La construcción de la Iglesia en los Andes (siglos XVI-XX), pp. 523-561. Lima: PUCP.

Arrelucea Barrantes, Maribel y Jesús A. Cosamalón Aguilar (2015). La presencia afrodescendiente en el Perú. Siglos XVI-XX. Lima: Ministerio de Cultura.

Benito, José A. (2005). Historia del Señor de los Milagros de las Nazarenas. En Francesco Pini, Rodolfo (comp.), El rostro de un pueblo. Estudios sobre el Señor de los Milagros (pp. 133-257). Lima: Universidad Católica Sedes Sapientae.

Bernand, Carmen (2001). Negros esclavos y libres en las ciudades hispanoamericanas. Madrid: Fundación Histórica Tavera.

Bourdieu, Pierre (2009). La eficacia simbólica. Buenos Aires: Biblos.

Brubaker, Rogers y Frederick Cooper (2001). Más allá de «identidad». Apuntes de Investigación del CECYP.

Burga, Manuel (1999). La imagen nacional del Perú en su historia. En Adrián Bonilla, Ecuador-Perú. Horizontes de la negociación y el conflicto (pp. 139 152). Quito/ Lima: Flacso/Desco.

Carvalho, José Jorge (2000). A religião como sistema simbólico. Uma atualização teórica. Série Antropologia, 285. Brasilia.

Costilla, Julia (2011). El culto limeño al Señor de los Milagros (siglos XVII XXI): fundamentos históricos para repensar una devoción mestiza. Revista Peruana de Historia Eclesiástica, 13, 169-204. Lima: Academia Peruana de Historia Eclesiástica. 
Costilla, Julia (2014). Luchas hermenéuticas, identidades y usos estratégicos del milagro en la elaboración y apropiación de cultos cristianos (siglos XVII a XXI-Perú, Bolivia y Argentina). Tesis de Doctorado en Antropología. Buenos Aires: UBA.

Costilla, Julia (2015). "Guarda y custodia” en la Ciudad de los Reyes: la construcción colectiva del culto al Señor de los Milagros (Lima, siglos XVII-XVIII). Fronteras de la Historia 20(2), 152-179. Bogotá: ICAH.

Costilla, Julia (2016). Itinerarios antropológicos para una etnohistoria comparada de la religión. Diálogo Andino, 49, 299-309. Arica: UNT. http://dx.doi.org/10.4067/ S0719-26812016000100028

Cruz, Anthony de la (1984). Cofradias Negras en el Perú Colonial. Tesis de Bachiller en Historia. Pontificia Universidad Católica del Perú.

Durkheim, Emile (1968 [1912]). Las formas elementales de la vida religiosa. Buenos Aires: Shapire.

Escalona Téllez, Trinidad y Gabriela Gutiérrez Espinosa (1993). El Señor de los Milagros en el proceso político del Perú. Perú contemporáneo: el espejo de las identidades. En Ricardo Melgar Bao y María Teresa Bosque Lastra (comps). México: UNAM

Espezúa Echevarría, Elizabeth (2004). Práctica y vida religiosa de los cargadores del Señor de los Milagros. Lima: UNMSM. Tesis digitales UNMSM, febrero 2012.

Geertz, Clifford (1987). La interpretación de las culturas. México DF: Gedisa.

Geertz, Clifford (1994). Conocimiento local. Barcelona: Paidós.

Hampe Martínez, Teodoro (1996). Santa Rosa de Lima y la identidad criolla en el Perú colonial: ensayo de interpretación. Revista de Historia de América, 121, 7-26.

Klaiber, Jeffrey L. (1996). La Iglesia en el Perú: su historia social desde la independencia. Lima: PUCP.

Lorandi, Ana María (2012) ¿Etnohistoria, Antropología Histórica o simplemente Historia? Memoria Americana 20-1 [en línea]. Buenos Aires: ICA, FFyL, UBA.

Manrique, Nelson (1995). Bolivia y Perú: la fraternidad escindida. En AA.VV., Perú Bolivia. Forjando la integración. Lima: Fundación Friedrich Ebert.

Matos Mar, José (2010). Presentación. En INDEPA, Aportes para un enfoque intercultural. Lima: INDEPA.

Mujica Pinilla, Ramón (2001). Rosa Limensis. Mística, política e iconografía en torno a la patrona de América. Lima: IFEA/FCE/BCRP.

Orrego Penagos, Juan Luis (2008). La independencia del Perú: el sesquicentenario (1971). Rumbo al Bicentenario [blog de Juan Luis Orrego Penagos] 11/6/2008. Lima: PUCP, noviembre de 2013. 
Panfichi Huaman, Aldo Italo (2000). Africanía, barrios populares y cultura criolla a inicios del siglo XX. En AA. VV., Lo africano en la cultura criolla (pp. 137-156). Lima: Fondo Editorial del Congreso del Perú.

Ricoeur, Paul (1976). Introducción a la simbólica del mal. Buenos Aires: Megápolis.

Rodríguez Pastor, Humberto (2008). Negritud: afroperuanos, resistencia y existencia. Lima: Centro de Desarrollo Étnico.

Rojas Dávila, Roberto (2008). La invisibilización de la población afroperuana. En Programa Andino de Derechos Humanos. Quito: Universidad Andina Simón Bolivar.

Rostworowski, María (1992). Pachacamac y el Señor de los Milagros. Una trayectoria milenaria. Lima: IEP.

Sánchez Rodríguez, Suzy (2002). Un Cristo Moreno “conquista” Lima: los arquitectos de la fama pública del Señor de los Milagros (1651-1771). En: AA.VV. Etnicidad y discriminación racial en la historia del Perú (pp. 65-93). Lima: PUCP/IRA/ Banco Mundial.

Turner, Víctor (1980). La selva de los símbolos. Madrid: Siglo XXI.

Valdivia Vargas, Néstor (2013). Las organizaciones de la población afrodescendiente en el Perú: discursos de identidad y demandas de reconocimiento. Lima: GAD.

Vargas Puch, Eduardo (1990). El culto al Señor de los Milagros. Producción y reproducción ideológica y política. Cuadernos de Sociología, I, 38-75. Lima.

Volóshinov, Valentín N. (2009 [1929]). El marxismo y la filosofía del lenguaje. Buenos Aires: Godot. 